\title{
Helistroke: Neurointerventionalist Helicopter Transport for Interventional Stroke Treatment: A Short Commentary
}

\section{Amgad El Mekabaty ${ }^{1}$ and Ferdinand Hui ${ }^{2 *}$}

1 Institute of Diagnostic and Interventional Neuroradiology, University Hospital of Bern -Inselspital, Bern, Switzerland

${ }^{2}$ Division of Interventional Neuroradiology, Russell H Morgan Department of Radiology and Radiological Science, Johns Hopkins University Hospital, Baltimore, Maryland, USA

\begin{abstract}
Recent randomized controlled trials have shown the efficacy of endovascular therapy in acute ischemic stroke due to large vessel occlusion. A pooled analysis of these trials has confirmed the known fact that time to intervention is a significant independent factor in good outcome in ischemic stroke. In order to reduce patient transfer time to an endovascular-capable stroke center, we analyzed the workflow in a novel case of helicopter transfer of neurointerventionalist to a stroke patient in a primary stroke center. This proof of concept case demonstrates the feasibility of such a process and offers an additional tool in advancing endovascular therapy in acute ischemic stroke.
\end{abstract}

Keywords: Helistroke; Large vessel occlusion-acute ischemic stroke (LVO-AIS); Stroke workflow analysis

\section{Introduction}

Endovascular therapy for acute ischemic stroke (AIS) is becoming the standard of care for patients with large vessel occlusion (LVO) [1]. Timely intervention is hereby recognized as an independent factor for long term good clinical outcome in those patients [2]. Current workflow paradigms in acute stroke emphasize on patient transfer to a stroke center; either a primary stroke center for evaluation first or directly to an endovascular-capable stroke center. In an attempt to reduce patient transfer time, we report the first case [3] of helicopter transfer of neurointerventionalist to a primary stroke center for endovascular treatment of a patient with acute stroke.

\section{Endovascular Treatment in LVO-AIS}

In the past years, multiple randomized control trials $[1,4-6]$ have provided level I evidence for the efficacy of endovascular thrombectomy treatment in AIS-LVO patients with recanalization success rate of up to $90 \%$. While there were differences in determining the optimal selection criteria of patients who would profit from endovascular treatment between studies, it was evident that time to intervention was a significant independent predictor of good clinical outcome (defined as modified Rankin score "mRS" 0-2). In a recent analysis there was $91 \%$ probability of good clinical outcome in case of endovascular treatment within 150 min of onset, with $10 \%$ reduction in good clinical outcome 60 min later and even $20 \%$ more reduction in the next $60 \mathrm{~min}$ [7]. In light of the recent trials, endovascular treatment in AIS-LVO amounts to a standard of care in stroke patients.

\section{Common Workflow Patterns in Acute Stroke}

Two commonly reported workflow patterns in managing AIS patients include "spoke and hub" and "mothership" models [8]. In "spoke and hub" approach stroke patients are evaluated in primary stroke centers (i.e. with no endovascular capability) and i.v. tPA (intravenous tissue plasminogen activator) is administered and transfer to a comprehensive stroke center (i.e. with endovascular capability), usually within the same regional network of healthcare providers, when needed for interventional stroke treatment. In "mothership" approach patients with suspected AIS-LVO are transferred directly to the comprehensive stroke center for evaluation and administration of either medical or endovascular treatment in case of a confirmed diagnosis. Depending on geographical and regional characteristics however, patient transfer in both models can be time consuming and delay in patient transfer could negatively impact the clinical outcome of stroke treatment.

\section{Helistroke}

In a proof of concept case [3], a neurointerventionalist flew with a helicopter from our comprehensive stroke center upon notification of an acute stroke case with LVO to a primary stroke center in the same hospital network, which is located 39.4 miles away (flight duration: $19 \mathrm{~min}$ ). Endovascular treatment was performed by the neurointerventionalist with assistance of the local care team. Analysis of workflow and procedural times revealed a total neurointerventionalist transfer time of $43 \mathrm{~min}$ (from patient arrival at primary stroke hospital to neurointerventionalist arrival at angiography suite). In comparison, an analysis of aggregate patient transfer data in the same state showed an average total patient transfer time of $131 \mathrm{~min}$ (from patient arrival in primary stroke center to patient arrival in angiography suite at the comprehensive stroke center). In our hospital network, the cost of the neurointerventionalist transfer was $20 \%$ of that of patient transfer.

In the next step, we will be analyzing workflow metrics in our future helistroke cases to examine the consistency of the reduction in time to recanalization and both economical and clinical benefit of such a novel workflow model in acute LVO stroke patients. There are many questions regarding the optimal configuration of such a helistroke model, such as the availability of equipment and trained assisting personnel at the primary stroke center, off-hour coverage at the comprehensive stroke center while the neurointerventionalist is on a helistroke mission and economical benefit. Yet, such a model offers more options to policy makers, assisting in advancing stroke care, especially to otherwise geographically disadvantaged regions.

*Corresponding author: Ferdinand Hui, MD, Division of Interventional Neuroradiology The Johns Hopkins Hospital, 1800 Orleans Street, Baltimore, MD 21278 USA, Tel: +1410-955-8525; E-mail: ferdinandhui@gmail.com

\section{Received April 30, 2018; Accepted May 17, 2018; Published May 24, 2018}

Citation: Mekabaty AEI, Hui F (2018) Helistroke: Neurointerventionalist Helicopter Transport for Interventional Stroke Treatment: A Short Commentary. Int J Neurorehabilitation 5: 321. doi: 10.4172/2376-0281.1000321

Copyright: ( $) 2018$ Mekabaty AEl, et al. This is an open-access article distributed under the terms of the Creative Commons Attribution License, which permits unrestricted use, distribution, and reproduction in any medium, provided the original author and source are credited. 
Citation: Mekabaty AEI, Hui F (2018) Helistroke: Neurointerventionalist Helicopter Transport for Interventional Stroke Treatment: A Short Commentary. Int J Neurorehabilitation 5: 321. doi: 10.4172/2376-0281.1000321

\section{Conclusion}

This proof of concept case demonstrated the feasibility of a novel workflow model in acute stroke, resulting in a relevant reduction in transfer time by flying the neurointerventionalist to the patient at the primary stroke center to administer endovascular therapy. Further studies are needed to examine the efficacy of such a model on a larger scale.

\section{References}

1. Goyal M, Demchuk AM, Menon BK, Eesa M, Rempel JL, et al. (2015) Randomized assessment of rapid endovascular treatment of ischemic stroke. N Engl J Med 372: 1019-1030.

2. Khatri P, Abruzzo T, Yeatts SD, Nichols C, Broderick JP, et al. (2009) Good clinical outcome after ischemic stroke with successful revascularization is timedependent. Neurology 73: 1066-1072.

3. Hui FK, El Mekabaty A, Schultz J, Hong K, Horton K, et al. (2018) Helistroke: Neurointerventionalist helicopter transport for interventional stroke treatment: Proof of concept and rationale. J Neurointerv Surg 10: 225-228.
4. Campbell BC, Mitchell PJ, Kleinig TJ, Dewey HM, Churilov L, et al. (2015) Endovascular therapy for ischemic stroke with perfusion-imaging selection. $\mathrm{N}$ Engl J Med 372: 1009-1018.

5. Berkhemer OA, Fransen PS, Beumer D, van den Berg LA, Lingsma HF, et al (2015) A randomized trial of intraarterial treatment for acute ischemic stroke. $\mathrm{N}$ Engl J Med 372: 11-20.

6. Saver JL, Goyal M, Bonafe A, Diener HC, Levy El, et al. (2015) Stent-retriever thrombectomy after intravenous t-PA vs. t-PA alone in stroke. $\mathrm{N}$ Engl J Med 372: 2285-2295.

7. Goyal M, Jadhav AP, Bonafe A, Diener H, Mendes PV, et al. (2016) Analysis of workflow and time to treatment and the effects on outcome in endovascular treatment of acute ischemic stroke: Results from the swift prime randomized controlled trial. Radiology 279: 888-897.

8. Menon BK, Sajobi TT, Zhang Y, Rempel JL, Shuaib A, et al. (2016) Analysis of workflow and time to treatment on thrombectomy outcome in the endovascular treatment for small core and proximal occlusion ischemic stroke (ESCAPE) randomized, controlled trial. Circulation 133: 2279-2286. 